\title{
Past cervical intraepithelial neoplasia grade 3, obesity, and earlier menopause are associated with an increased risk of vulval cancer in postmenopausal women
}

\author{
Kate Coffey ${ }^{1}$, Kezia Gaitskell ${ }^{1}$, Valerie Beral ${ }^{1}$, Karen Canfell ${ }^{2,3}$, Jane Green ${ }^{1}$, Gillian Reeves ${ }^{1}$ and \\ Isobel Barnes ${ }^{\star}, 1$ on behalf of the Million Women Study Collaborators ${ }^{4}$ \\ ${ }^{1}$ Cancer Epidemiology Unit, University of Oxford, Richard Doll Building, Old Road Campus, Roosevelt Drive, Oxford, OX3 7LF, UK; \\ ${ }^{2}$ Cancer Research Division, Cancer Council NSW, Woolloomooloo, New South Wales 2011, Australia and ${ }^{3}$ School of Public Health, \\ Sydney Medical School, University of Sydney, Sydney, New South Wales, Australia
}

Background: Vulval cancer predominantly affects postmenopausal women. A smaller proportion of vulval cancers, particularly at older ages, are now thought to be associated with human papillomavirus infection than previously reported, but other risk factors have not been well examined in prospective cohort studies.

Methods: A total of 1.3 million women aged 49-65 years were followed for incident vulval cancer (ICD-10 C51). Adjusted Cox regression models were used to examine the relationship between reproductive and lifestyle factors and risk of vulval cancer.

Results: There were 898 vulval cancers registered in the cohort over an average of 14 years of follow-up; $70 \%$ were squamous cell carcinomas. Past registration of cervical carcinoma in situ (RR 2.68; 95\% Cl 1.71-4.18; $P<0.001$ ), obesity (RR 1.71; 95\% Cl 1.44-2.04; $P<0.0001$ ), and menopause before the age of 50 years (RR 1.52; 95\% Cl 1.22-1.89; $P<0.001$ ) were associated with a significantly increased risk of subsequent vulval cancer.

Conclusion: Past cervical pre-cancer, obesity, and earlier age at menopause are associated with an increased risk of vulval cancer at older ages.

Although vulval cancer accounts for $<1 \%$ of all female cancer, it is the most common anogenital cancer in women over 70 years (Figure 1). In 2012, there were 1052 vulval cancers registered in England, of which $86 \%$ (909 cases) were in women aged over 50 years. Its annual incidence increases markedly with age, rising from 2.5 cases per 100000 women at ages $40-44$ years to 17.0 per 100000 at ages 80-84 years (Office for National Statistics, 2014).

It has been shown that the risk of vulval cancer is associated with cervical intraepithelial neoplasia (CIN) and that vulval cancer has aetiopathological similarities with high-risk human papillomavirus (HrHPV)-related cancers such as cervical, anal, and vaginal cancers (Kalliala et al, 2005; Crawford et al, 2011). Until recently, it was thought that $\sim 40 \%$ of vulval cancer cases were attributable to HrHPVs (Chaturvedi, 2010). However, it now seems that a decreasing proportion of vulval cancers are associated with $\mathrm{HrHPV}$ as women age; it has been reported that only $15-17 \%$ of cases in women aged $\geqslant 67$ years are associated with $\mathrm{HrHPV}$ infection (de Sanjosé et al, 2013). Vulval cancers in older women are thought to be more likely to arise in a background of vulval dermatosis (van de Nieuwenhof et al, 2009), and less likely to be

*Correspondence: Dr I Barnes; E-mail: isobel.barnes@ceu.ox.ac.uk

${ }^{4}$ Members of the Million Women Study Collaborators are listed before References.

Received 10 November 2015; revised 8 April 2016; accepted 30 April 2016; published online 23 June 2016

(c) 2016 Cancer Research UK. All rights reserved 0007 - 0920/16 


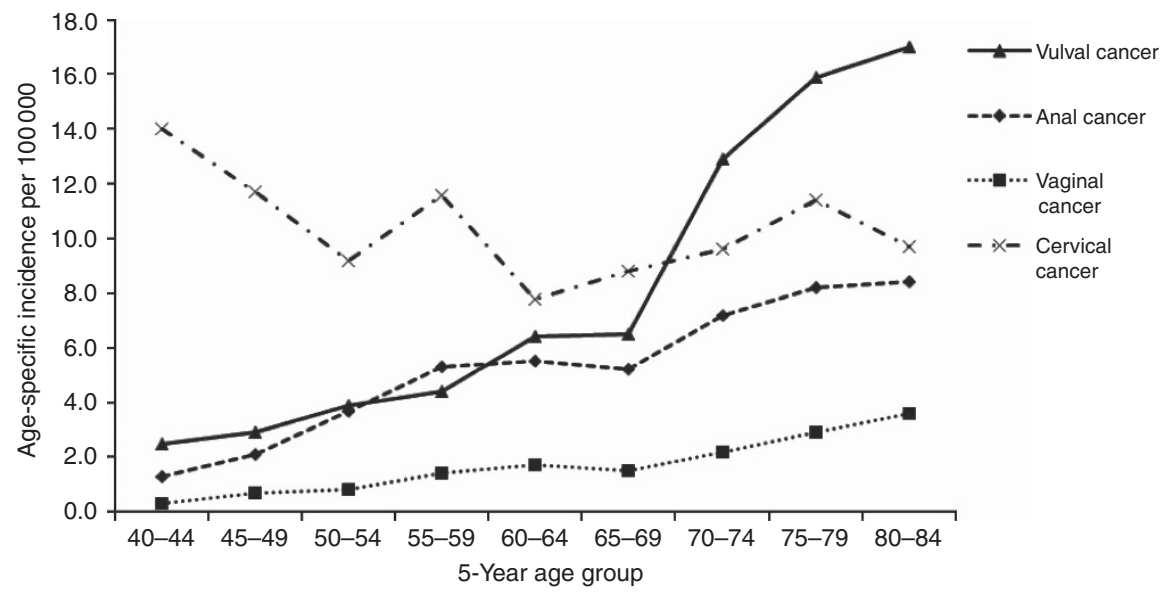

Figure 1. Age-specific rates of vulval cancer (ICD-10 C51) compared with cervical (C53), anal (C21), and vaginal (C52) cancer, England 2012. Rates are per 100000 women by 5-year age groups, starting at age 40 years (Office for National Statistics, 2014).

HrHPV driven. In addition, cohort period and age effects relating to HrHPV exposure are likely to play a role (Barlow et al, 2015).

Most previous epidemiological studies of risk factors have been small and no consistent findings have emerged (Japaze et al, 1977; Newcomb et al, 1984; Brinton et al, 1990; Parazzini et al, 1993; Madsen et al, 2008). Some uncontrolled case series suggested a relationship between obesity and vulval cancer risk (Green et al, 1958; Franklin and Rutledge, 1972); however, a 2013 review concluded that although there may be a relationship between adiposity and vulval cancer, studies had been too small to answer the question definitively (Webb, 2013).

We investigated risk factors for vulval cancer in a large cohort of UK women aged $\geqslant 50$ years, examining associations for vulval cancer overall, and by histological subtype, with obesity, diabetes, and various lifestyle and reproductive risk factors including smoking, parity, past cervical dysplasia, age at menopause, and use of oral contraceptives and menopausal hormone therapy (HT).

\section{MATERIALS AND METHODS}

The Million Women Study is a large prospective cohort study that recruited 1.3 million women invited for routine breast screening via the National Health Service Breast Screening Programme (NHSBSP) between 1996 and 2001 (i.e. women who were born between 1931 and 1952). Full details of the study design and methods are described elsewhere (Beral et al, 2003). Study questionnaires and further details of the data and access policies can be viewed online at www.millionwomenstudy.org.

Study participants completed a baseline questionnaire providing self-reported information on lifestyle, health and reproductive exposures. Participants were resurveyed twice, $\sim 4$ and 8 years after recruitment. The study has Multi-Centre Research Ethics Committee approval (MREC 97/01).

The study teams are provided with regularly updated information on incident cancers and deaths via the UK National Health Service Central Registers (NHSCR). Cases of incident vulval cancer were identified as 'malignant neoplasm of vulva', International Classification of Diseases, version 10 (ICD-10) (World Health Organization 2011) C51. We used self-reported data from the recruitment questionnaire to define most exposures, including menopausal HT use. Excellent agreement has been found between HT use as reported by Million Women Study participants and general practice records in a past validation study (Banks et al, 2001).
Marital status and history of cervical screening were based on self-reported data from the first resurvey, when information on these exposures was first collected. The Townsend Deprivation Index (Townsend, 1987) was calculated using post-code and 1991 census data. Body mass index was calculated from self-reported weight and height measurements at recruitment that have been shown to correlate closely with measured variables in Million Women Study participants (Bobrow et al, 2012). Women with a registration of $\mathrm{CIN}$ grade 3 (CIN 3) before recruitment were identified using the information provided by NHSCR.

Vulval cancers were divided into four main histological subtypes: squamous cell carcinomas (SCCs), basal cell carcinomas (BCCs), glandular tumours, and melanocytic tumours. Histological subtypes were identified using ICDO-3 (International Classification of Diseases for Oncology version 3) morphology codes (World Health Organization, 2000; Kurman et al, 2014).

Squamous tumours included the following ICDO-3 codes: M8051/3, M8070/3, M8070/5, M8071/3, M8072/3, M8074/3, M8075/3; and M8076/3. Basal cell carcinomas included: M8090/3, M8091/3, M8094/3, and M8097/3. Glandular tumours (including Paget's disease, Bartholin gland tumours, and adenocarcinomas) were: M8140/3, M8200/3, M8390/3, M8400/3, M8480/3, M8542/3, and M8560/3. Finally, melanocytic tumours included: M8720/3, M8721/3, M8743/3, M8744/3, and M8746/3. Other rarer tumour types were excluded from the analysis, and these included unclassified malignancies and sarcomas (see the Results section for further enumeration of 'other' tumour histologies).

Statistical analyses. Participants were excluded from the analyses if they had any invasive cancer registered before the start of followup, other than non-melanoma skin cancer (ICD-10 C44). For analyses of all exposures apart from marital status and history of cervical screening, follow-up started on the date of recruitment or at the age of 50 years for the small number of women $(3 \%)$ who were $<50$ years old at recruitment. For marital status and history of cervical screening, follow-up started on the date that participants completed the first resurvey. Follow-up continued until the earliest of: the date of registration of any cancer; death; emigration or other loss to follow-up; or 31 December 2013, the end of follow-up.

We used Cox proportional hazard models with attained age as the underlying time variable to estimate hazard ratios (referred to as relative risks (RRs)) of developing vulval cancer in relation to the following exposures: smoking (never, past, current); alcohol (0-2, $3+$ units per week); BMI (normal: $<25 \mathrm{~kg} \mathrm{~m}^{-2}$, overweight: 25-29 $\mathrm{kg} \mathrm{m}^{-2}$, obese: $30+\mathrm{kg} \mathrm{m}^{-2}$ ); diabetes (no, yes); oral contraceptive use (never, ever); parity (parous, nulliparous); prior hysterectomy (no, with oophorectomy, without oophorectomy); 
prior CIN 3 registration (no, yes); deprivation (tertiles); marital status (married/living with a partner, or not); past cervical screening (no, yes); age at menopause $(<50,50+$ years); and HT use (never, past, current).

All analyses were, where possible, mutually adjusted for exposures. In addition, all analyses were stratified by region of residence consisting of 10 geographical areas corresponding to the cancer registry regions: Oxford, East Anglia, South West, Thames, West Midlands, Northern and Yorkshire, Trent, North West (Mersey), North West (Manchester/Lancashire), and Scotland. The assumption of proportional hazards was examined using plots of the Schoenfeld residuals and was found to be reasonable.

In order to avoid distortion by HT use, analyses of age at menopause were restricted to women who reported at baseline that they had never used HT and that they either had a natural menopause or had a bilateral oophorectomy. Analyses of HT use were restricted to women who reported being post-menopausal at baseline.

A subgroup analysis was performed using a competing hazards model to examine the associations between BMI $(<30,30+$ $\left.\mathrm{kg} \mathrm{m}^{-2}\right)$, smoking (never, ever), age at menopause $(<50,50+$ years), menopausal HT use (never, past, current), and vulval cancer by histological subtype. Results were tested for heterogeneity of effect of these exposures by tumour histological type. We were unable to look at the effect of CIN 3 by histology because of the small number of cases with this exposure within subtype groups.

We performed two sensitivity analyses. In the first, we excluded the first years of follow-up from the main analysis to assess the possibility of reverse association. In the second, we assessed the possibility of bias due to changes in exposures over the follow-up period. To do this we censored women who did not respond to a resurvey 4 years after their previous survey. We then compared an analysis in which exposures were fixed at recruitment to one in which smoking status, alcohol use, BMI, diabetes, and hysterectomy/oophorectomy were updated using self-reported data from the first and second resurveys, and CIN 3 registration was updated using data provided by the NHSCR.

The few women with missing data for adjustment variables $(<5 \%$ for each variable) were included in a separate category for each variable of interest. Relative risks are reported with $95 \%$ confidence intervals (CIs). Analyses were performed in Stata 14 (Statacorp, 2015).

\section{RESULTS}

A total of 1.3 million women without prior cancer were followed for 18 million person-years (on average 13.8 years per woman), and there were 898 vulval cancers registered in the cohort over that period. Just over half of the cohort were overweight or obese: $34 \%$ of women had a BMI of 25 to $29.9 \mathrm{~kg} \mathrm{~m}^{-2}$, putting them in the overweight range, and $17 \%$ were obese with a BMI of $\geqslant 30 \mathrm{~kg} \mathrm{~m}^{-2}$. Most women were parous, with $89 \%$ of participants reporting ever having given birth. Nearly $60 \%$ had a history of oral contraceptive use, $46 \%$ had ever smoked, with 19\% reporting being current smokers. Around half of all participants had ever used menopausal hormone therapy (Table 1).

The exposure with the strongest association with risk of vulval cancer later in life was a registration of CIN 3 before recruitment. Women with a CIN 3 registration before recruitment had more than a doubling in risk of vulval cancer compared with women who had not had CIN 3 (RR 2.68; 95\% CI 1.71-4.18; $P<0.0001$ ).

Being overweight or obese was associated with an increased risk of vulval cancer compared with women with a normal BMI and risk increased with adiposity. Overweight women (BMI of
Table 1. Participant characteristics at baseline, and details of follow-up in the cohort

Characteristic at baseline

\section{Number of women (\%)}

Mean age at recruitment (s.d.)

Parous, \% (n)

Oral contraceptive user (ever), \% (n)

Current smoker, \% ( $n$ )

Body mass index $\geqslant 30 \mathrm{~kg} \mathrm{~m}^{-2}, \%(n)$

Most deprived tertile, \% (n)

Ever hormone therapy user, \% (n)

Hysterectomy, \% (n)

Registration of CIN 3 before recruitment, \% (n)

$1300042(100.0)$

$56.6(4.8)$

89.0 (1 157 188)

$58.6(761700)$

$19.2(249014)$

$17.0(220976)$

$33.0(428383)$

$49.6(644804)$

$24.4(316927)$

$1.0(12533)$

Follow-up

\section{Women-years (1000s)}

Mean length of follow-up per woman (s.d.)

Number of women with incident vulval cancer

Abbreviation: CIN $3=$ cervical intraepithelial neoplasia grade 3 .

17956

$13.8(3.4)$ 898

$25-29 \mathrm{~kg} \mathrm{~m}^{-2}$ ) had a $19 \%$ increase in risk of incident vulval cancer, with a RR of 1.19 (95\% CI 1.02-1.39; $P<0.0001)$, and this rose further in women classed as obese (BMI of $\geqslant 30 \mathrm{~kg} \mathrm{~m}^{-2}$ ), who had a RR of 1.71 (95\% CI 1.44-2.04; $P<0.0001$; Figure 2). After adjustment for BMI and other factors, there was no significant increase in risk associated with a history of diabetes.

There was no association seen between smoking and overall vulval cancer risk; women who reported ever having smoked had a RR of 0.98 (95\% CI 0.82-1.17) compared with never smokers. Similarly, no significant increase in risk was seen with alcohol use, age at menarche, oral contraceptive pill use, parity, or tubal ligation.

We examined risk associated with age at menopause in women who had never used menopausal HT and who reported a natural menopause or bilateral oophorectomy. Women with an earlier age at menopause had an increased risk of vulval cancer later in life. Menopause before age 50 years was associated with a 50\% increase in risk of vulval cancer compared with menopause that occurred after 50 years (RR 1.52; 95\% CI 1.22-1.89; $P<0.001$ ). There did not appear to be any further increase in risk associated with age at menopause before age 45 years (RR 1.39; 95\% CI 1.00-1.94) compared with menopause at $45-49$ years (RR 1.58 ; 95\% CI $1.24-$ 2.01). Use of menopausal hormone therapy was not associated with risk of subsequent vulval cancer overall (Table 2).

In analyses starting at the first resurvey at $\sim 4$ years after recruitment, when women were asked for the first time about marital status and attendance for cervical screening, there was no significant difference in risk of vulval cancer for women not currently married or living with a partner (RR 1.19; 95\% CI 0.951.50) compared with those who were; or for those who reported having ever $v s$ never attended for cervical screening (RR 0.96; 95\% CI 0.57-1.62).

Two-thirds of vulval cancers $(n=609,68 \%)$ were specified as squamous cell carcinomas. Glandular tumours were less common, with 96 registered (11\%), including Paget's disease and various types of adenocarcinoma. Basal cell tumours were the next most common, with 92 cases (10\%). Melanocytic $(n=55,6 \%)$ and other (unspecified and sarcomatous) tumours made up the remaining number $(n=46,5 \%)$ (Table 3$)$.

When we examined associations by histological subtype (Table 4), obese women (BMI of $30+\mathrm{kg} \mathrm{m}^{-2}$ ) had a substantially and significantly elevated risk of squamous cell carcinoma (RR 1.84; 95\% CI 1.53-2.21), but little or no associated increased risk for basal cell, glandular, or melanocytic tumours (test for heterogeneity $P=0.01)$. We also observed a reduction in melanocytic tumours in women who had ever smoked (RR 0.49; 95\% CI 0.27-0.91) compared with never smokers. 


\begin{tabular}{|c|c|c|c|}
\hline & Cases & Relative risk $(95 \% \mathrm{Cl})$ & Relative risk $(95 \% \mathrm{Cl})$ \\
\hline \multicolumn{4}{|l|}{ Smoking } \\
\hline Never & 456 & 1.00 & 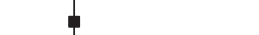 \\
\hline Past & 219 & $0.88(0.75-1.04)$ & $\rightarrow+$ \\
\hline Current & 168 & $1.04(0.87-1.26)$ & - \\
\hline \multicolumn{4}{|l|}{ Alcohol (units per week) } \\
\hline $0-2$ & 585 & 1.00 & $\phi$ \\
\hline $3+$ & 305 & $0.87(0.75-1.00)$ & $\rightarrow$ \\
\hline \multicolumn{4}{|l|}{ Body mass index } \\
\hline Under 25 & 327 & 1.00 & 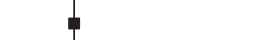 \\
\hline $25-29$ & 311 & $1.19(1.02-1.39)$ & - \\
\hline $30+$ & 218 & $1.71(1.44-2.04)$ & $\longrightarrow$ \\
\hline \multicolumn{4}{|l|}{ Diabetes } \\
\hline No & 872 & 1.00 & $\phi$ \\
\hline Yes & 25 & $0.87(0.58-1.30)$ & $\rightarrow-$ \\
\hline \multicolumn{4}{|l|}{ Age at menarche } \\
\hline 13 and under & 534 & 1.00 & 1 \\
\hline $14+$ & 343 & $1.04(0.90-1.19)$ & - \\
\hline \multicolumn{4}{|l|}{ Oral contraceptive use } \\
\hline Never & 403 & 1.00 & 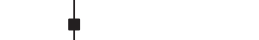 \\
\hline Ever & 481 & $1.08(0.94-1.24)$ & - \\
\hline \multicolumn{4}{|l|}{ Parity } \\
\hline Parous & 789 & 1.00 & 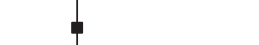 \\
\hline Nulliparous & 108 & $1.19(0.97-1.47)$ & $\rightarrow-$ \\
\hline \multicolumn{4}{|l|}{ Prior tubal ligation } \\
\hline No & 691 & 1.00 & 1 \\
\hline Yes & 187 & $0.91(0.77-1.07)$ & $\rightarrow$ \\
\hline \multicolumn{4}{|l|}{ Prior hysterectomy } \\
\hline No hysterectomy & 650 & 1.00 & 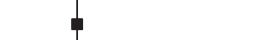 \\
\hline With oophorectomy & 68 & $1.08(0.83-1.39)$ & - \\
\hline Without oophorectomy & 117 & $0.98(0.80-1.19)$ & $\rightarrow-$ \\
\hline \multicolumn{4}{|c|}{$\begin{array}{l}\text { Cervical intraepithelial neoplasia grade } 3 \\
\text { registration before recruitment }\end{array}$} \\
\hline No & 878 & 1.00 & 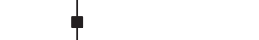 \\
\hline Yes & 20 & $2.68(1.71-4.18)$ & \\
\hline \multicolumn{4}{|l|}{ Deprivation (tertiles) } \\
\hline 1: Least deprived & 288 & 1.00 & 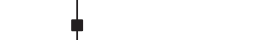 \\
\hline 2 & 274 & $0.94(0.79-1.10)$ & - \\
\hline \multirow[t]{2}{*}{ 3: Most deprived } & 336 & $1.11(0.94-1.30)$ & $t=-$ \\
\hline & & $\begin{array}{l}1 \\
0\end{array}$ & 1 \\
\hline
\end{tabular}

Figure 2. Association between vulval cancer and various lifestyle and other factors. Relative risks adjusted, where possible, for smoking, alcohol use, body mass index, diabetes, age at menarche, oral contraceptive use, parity, prior tubal ligation, prior hysterectomy, cervical intraepithelial neoplasia grade 3 before recruitment, and deprivation.

Table 2. Associations between risk of vulval cancer, age at menopause, and use of menopausal hormone therapy in postmenopausal women

\begin{tabular}{|l|c|c|c|c|}
\hline Exposure & Cases/population at risk & Relative risk ${ }^{\text {a }}$ & 95\% Confidence interval & $P$-value \\
\hline Age at menopause in women with natural menopause or oophorectomy who have never used hormone therapy \\
\hline $50+$ Years & $158 / 237144$ & 1.00 & $(1.22-1.89)$ & $<0.001$ \\
$<50$ Years & $167 / 175489$ & 1.52 & \\
\hline Use of menopausal hormone therapy at baseline, all postmenopausal women & $(0.77-1.14)$ & $(0.73-1.02)$ \\
\hline Never & $401 / 493167$ & 1.00 & 0.94 \\
Past & $142 / 192727$ & 0.86 & \\
Current & $252 / 424544$ & & \\
\hline a Relative risks adjusted, where possible, for smoking, alcohol use, body mass index, age at menarche, oral contraceptive use, parity, tubal ligation, cervical intraepithelial neoplasia grade 3, \\
diabetes, hysterectomy/oophorectomy, and deprivation.
\end{tabular}


Table 3. Incident vulval cancer registrations in the cohort by histological subtype and International Classification of Diseases for Oncology, 3rd Edition (ICDO-3) morphology coding

\section{ICDO-3 morphology code}

Squamous tumours

\section{M8070/3}

$\mathrm{M} 8071 / 3$

M8070/5, M8076/3

$\mathrm{M} 8051 / 3$

M8072/3, 8074/3, 8075/3

\section{Histological subtype}

\section{Glandular tumours}

M8542/3

M8480/3,M8400/3, M8140/3

M8200/3, M8390/3, M8560/3

\begin{tabular}{|l|c} 
Squamous cell carcinoma, not otherwise specified & $447(50.0)$ \\
Squamous cell carcinoma, keratinising, not otherwise specified & $131(14.6)$ \\
Squamous cell carcinoma, microinvasive & $16(1.8)$ \\
Verrucous carcinoma, not otherwise specified & $8(0.9)$ \\
Squamous cell carcinoma: large cell, non-keratinising/spindle cell/adenoid & $7(0.8)$ \\
Total squamous cell tumours & $609(67.8)$
\end{tabular}

\section{Basal cell tumours}

\begin{tabular}{l|l} 
M8090/3 & Basal cell carcinoma, not otherwise specified \\
M8091/3 & Multifocal superficial basal cell carcinoma
\end{tabular}

$\mathrm{M} 8091 / 3$

$\mathrm{M} 8094 / 3, \mathrm{M} 8097 / 3$

\section{Paget's disease}

Adenocarcinoma: mucinous/sweat gland/not otherwise specified

Adenoid cystic/skin appendage/adenoquamous carcinoma

Total glandular tumours
Number (\% of all vulval cancers)

\section{Melanocytic tumours}

M8720/3

$\mathrm{M} 8721 / 3$

$\mathrm{M} 8743 / 3$

$\mathrm{M} 8744 / 3$

$\mathrm{M} 8746 / 3$

Basosquamous carcinoma, basal cell carcinoma (nodular)

Total basal cell carcinomas
$73(8.1)$

$13(1.4)$

$10(1.1)$

$96(10.7)$

\section{Other tumours: unspecified and sarcomatous}

Malignant melanoma, not otherwise specified

Nodular melanoma

Superficial spreading melanoma

Acral lentiginous melanoma, malignant

Mucosal lentiginous melanoma

Total melanocytic tumours
$80(8.9)$

$6(0.7)$

$6(0.7)$

$92(10.2)$

\section{M8000/3, 8010/3}

M8032/3, M8033/3, M8800/3, M8832/3,

$\mathrm{M} 8851 / 3, \mathrm{M} 8890 / 3, \mathrm{M} 8891 / 3$

Neoplasm/epithelial tumour, malignant

Spindle cell carcinoma, not otherwise specified/pseudosarcomatous carcinoma/sarcoma, not

otherwise specified/dermatofibrosarcoma, not otherwise specified/liposarcoma, well-

differentiated /leiomyosarcoma/epithelioid leiomyosarcoma

Total 'other' tumours

Total incident vulval cancers
$21(2.3)$

$16(1.8)$

14 (1.6)

4 (0.4)

55 (6.1)
37 (4.0)

$9(0.9)$

46 (5.1)

898 (100.0)

Table 4. Associations between body mass index, smoking, age at menopause, menopausal hormone therapy use, and risk of vulval cancer by tumour histology subtype

\begin{tabular}{|c|c|c|c|c|c|c|c|c|c|c|c|c|c|}
\hline \multirow[b]{2}{*}{ Exposure } & \multicolumn{3}{|c|}{ Squamous cell carcinoma } & \multicolumn{3}{|c|}{ Glandular tumours } & \multicolumn{3}{|c|}{ Basal cell carcinoma } & \multicolumn{3}{|c|}{ Melanocytic tumours } & \multirow[b]{2}{*}{$P$-value ${ }^{b}$} \\
\hline & $\begin{array}{c}\text { Cases/ } \\
\text { population } \\
\text { at risk }\end{array}$ & $\mathbf{R R}^{\mathrm{a}}$ & $95 \% \mathrm{Cl}$ & $\begin{array}{c}\text { Cases/ } \\
\text { population } \\
\text { at risk }\end{array}$ & $\mathrm{RR}^{\mathrm{a}}$ & $95 \% \mathrm{Cl}$ & $\begin{array}{c}\text { Cases/ } \\
\text { population } \\
\text { at risk }\end{array}$ & $\mathrm{RR}^{\mathrm{a}}$ & $95 \% \mathrm{Cl}$ & $\begin{array}{c}\text { Cases/ } \\
\text { population } \\
\text { at risk }\end{array}$ & $\mathbf{R R}^{\mathbf{a}}$ & $95 \% \mathrm{Cl}$ & \\
\hline \multicolumn{14}{|c|}{ Body mass index } \\
\hline $\begin{array}{l}<30 \\
30+\end{array}$ & $\begin{array}{c}406 / 1010993 \\
168 / 220976\end{array}$ & $\begin{array}{l}1.00 \\
1.84\end{array}$ & $(1.53-2.21)$ & $\begin{array}{c}78 / 1010993 \\
15 / 220976\end{array}$ & $\begin{array}{l}1.00 \\
0.87\end{array}$ & $(0.49-1.51)$ & $\begin{array}{c}76 / 1010993 \\
16 / 220976\end{array}$ & $\begin{array}{l}1.00 \\
1.03\end{array}$ & $(0.60-1.79)$ & $\begin{array}{c}43 / 10110993 \\
11 / 220976\end{array}$ & $\begin{array}{l}1.00 \\
1.20 \\
\end{array}$ & $(0.61-2.36)$ & 0.01 \\
\hline \multicolumn{14}{|l|}{ Smoking } \\
\hline $\begin{array}{l}\text { Never } \\
\text { Ever }\end{array}$ & $\begin{array}{l}294 / 627145 \\
276 / 596249\end{array}$ & $\begin{array}{l}1.00 \\
1.04\end{array}$ & $(0.88-1.23)$ & $\begin{array}{l}47 / 627145 \\
46 / 596249\end{array}$ & $\begin{array}{l}1.00 \\
1.13\end{array}$ & $(0.74-1.71)$ & $\begin{array}{l}52 / 627145 \\
34 / 596249\end{array}$ & $\begin{array}{l}1.00 \\
0.75\end{array}$ & $(0.48-1.17)$ & $\begin{array}{l}36 / 627145 \\
15 / 596249\end{array}$ & $\begin{array}{l}1.00 \\
0.49\end{array}$ & $(0.27-0.91)$ & 0.06 \\
\hline \multicolumn{14}{|c|}{ Age at menopause } \\
\hline $\begin{array}{l}50+\text { Years } \\
<50 \text { Years }\end{array}$ & $\begin{array}{l}112 / 237144 \\
122 / 175489\end{array}$ & $\begin{array}{l}1.00 \\
1.59\end{array}$ & $(1.22-2.06)$ & $\begin{array}{l}13 / 237144 \\
15 / 175489\end{array}$ & $\begin{array}{l}1.00 \\
1.62\end{array}$ & $(0.76-3.45)$ & $\begin{array}{l}15 / 237144 \\
15 / 175489\end{array}$ & $\begin{array}{l}1.00 \\
1.43\end{array}$ & $(0.69-2.97)$ & $\begin{array}{l}9 / 237144 \\
7 / 175489\end{array}$ & $\begin{array}{l}1.00 \\
1.17\end{array}$ & $(0.42-3.23)$ & 0.94 \\
\hline \multicolumn{14}{|c|}{ Menopausal hormone therapy use } \\
\hline $\begin{array}{l}\text { Never } \\
\text { Past } \\
\text { Current }\end{array}$ & $\begin{array}{c}288 / 493167 \\
87 / 192727 \\
159 / 424544\end{array}$ & $\begin{array}{l}1.00 \\
0.84 \\
0.82\end{array}$ & $\begin{array}{l}(0.66-1.07) \\
(0.66-1.00)\end{array}$ & $\begin{array}{l}35 / 493167 \\
20 / 192727 \\
33 / 424544\end{array}$ & $\begin{array}{l}1.00 \\
1.51 \\
1.26\end{array}$ & $\begin{array}{l}(0.87-2.65) \\
(0.76-2.09)\end{array}$ & $\begin{array}{c}34 / 493167 \\
20 / 192727 \\
25 / 424,54\end{array}$ & $\begin{array}{l}1.00 \\
1.69 \\
1.15\end{array}$ & $\begin{array}{l}(0.96-2.97) \\
(0.66-2.00)\end{array}$ & $\begin{array}{c}20 / 493167 \\
6 / 192727 \\
24 / 424544\end{array}$ & $\begin{array}{l}1.00 \\
0.79 \\
1.53\end{array}$ & $\begin{array}{l}(0.32-2.00) \\
(0.81-2.89)\end{array}$ & 0.28 \\
\hline
\end{tabular}

The sensitivity analyses showed that our results are not likely to be due to reverse association (Supplementary Figure 1). They also showed that any bias caused by changes in the exposures over time is likely to be small (Supplementary Figures 2 and 3 ).

\section{DISCUSSION}

The strongest increase in risk of vulval cancer in our study was seen in women with a registration of CIN 3 before recruitment, 
who had more than a doubling in risk compared with women who had not had CIN 3. Adiposity is also significantly associated with an increased risk of vulval cancer in women $>50$ years of age, principally in obese women, who have a $70 \%$ increase in vulval cancer incidence compared with those with a normal BMI; furthermore, the effect of BMI appears to be strongest for tumours with squamous cell morphology. Women who reported undergoing a natural or surgical menopause (oophorectomy) before age 50 years have a $52 \%$ increase in risk compared with those reporting a later menopause at $\geqslant 50$ years.

Risk of vulval cancer was not significantly associated with smoking; alcohol use; marital status; parity; hysterectomy; ever having attended for cervical cancer screening; diabetes; prior tubal ligation; age at menarche; or use of exogenous hormones in the form of the oral contraceptive pill or menopausal HT.

The HrHPV-related anogenital cancers are known to be related to previous genital tract dysplasia, typically screen-detected disease of the cervix (Crawford et al, 2011). A Finnish retrospective cohort study (Kalliala et al, 2005) has previously looked at risk of vulval cancer following a diagnosis of any grade of CIN. They found a standardised incidence ratio of 4.1 (95\% CI 1.5-8.9) for vulval cancer after treatment of CIN 1,2, or 3. This was based on 6 cases of vulval cancer among 7564 women who had been treated between 1974 and 2001 (with follow-up to 2003).

The relative risks reported here for vulval cancer after CIN 3, although substantial, are lower than those seen for anal cancer in our previously published study (Coffey et al, 2015). We found a RR of 4.03 for incident anal cancer in women with a history of CIN 3 registration before recruitment compared with the RR of 2.68 seen here for vulval cancer. Despite a strong association, vulval cancer remains an uncommon occurrence in women over 50 years with prior cervical neoplasia. In our cohort, 20 cases of vulval cancer arose in the 12533 women with a history of CIN 3. In other words, $\sim 1$ in 627 women with a history of CIN 3 have developed vulval cancer, and $2 \%$ of the vulval cancers in our study have occurred in women with prior CIN 3 (18 squamous cell carcinomas and 2 melanomas).

A relationship between vulval cancer and obesity has been suspected since the first case series on vulval cancer were published (Green et al, 1958; Franklin and Rutledge, 1972). Although one uncontrolled study from Johns Hopkins Hospital (Japaze et al, 1977) reported an increased prevalence of obesity among women with vulval cancer, other small case-control studies have found either a non-significant (Newcomb et al, 1984; Parazzini et al, 1993) or no increase in risk of vulval cancer associated with increased weight or BMI (Brinton et al, 1990). Some (Franklin and Rutledge, 1972; Brinton et al, 1990; Parazzini et al, 1993) have also suggested a relationship between vulval cancer and diabetes that we did not confirm with prospective evidence in our cohort.

Early age at menopause has also been linked with risk of vulval cancer (Green et al, 1958; Franklin and Rutledge, 1972). Franklin and Rutledge (1972) reported that 19\% of cases had undergone menopause (natural or surgical) before the age of 41 years, and $54 \%$ by the age of 45 years. Other small studies that examined the association with age at menopause and related factors (Newcomb et al, 1984; Parazzini et al, 1993) reported no significant effects of menopausal status, age at menopause, or HT use on risk of vulval cancer. An American case-control study (Brinton et al, 1990), which included 209 vulval cancer cases and 348 age-, race-, and residence-matched controls, found an increased risk among women with early ages at natural or surgical menopause: RR 1.89 (95\% CI 0.9-3.8) for surgical menopause at $<40$ years and $R R$ 1.75 (95\% CI 0.8-4.1) for natural menopause at $<45$ years, but this association did not reach statistical significance.

A Danish case-control study (Madsen et al, 2008) that included 116 vulval cancer cases found that around half of the vulval tumour samples they examined (compared with $89 \%$ of vaginal tumours in the same study) were positive for HrHPV. When they examined associations between vulval cancer and various exposures stratified by HrHPV positivity, they found significant associations with smoking and cervical neoplasia for only the HrHPV-positive cases.

We found no association between smoking and overall risk of vulval cancer, but when we stratified by tumour histological subtype, we saw a reduced risk of melanocytic vulval cancers among women who reported ever having smoked. This is based on a small number of cases in a subgroup analysis, and therefore must be interpreted with caution. However, other groups have reported similar findings for cutaneous malignant melanoma, with a decrease in incidence and mortality seen in smokers in a recent meta-analysis (Li et al, 2015).

A major strength of this study is that it is the first large prospective study to examine the risk of vulval cancer in older women, and our cohort has accrued a relatively large number of incident cases of this relatively uncommon cancer. In addition, CIN 3 status is obtained by routine reporting to cancer registries rather than potentially subjective self-reporting.

Although the number of incident cases of vulval cancers in this cohort is large, the relatively small numbers of cases within exposure subgroups limits our ability to analyse associations overall and by histological subtype. Another weakness lies in our inability to look at vulval dermatosis as an exposure, as we did not ask participants about vulval skin conditions. The vulval cancers that predominate at older ages are likely to be related to chronic vulval conditions, such as lichen sclerosis. It has been reported that $5 \%$ of women with symptomatic vulval lichen sclerosis have been found to develop squamous cell carcinomas, although $22 \%$ of women presenting with vulval cancers have been found to have 'clinically silent' lichen sclerosis adjacent to their tumours. An interval of $\sim 20$ years between mean age at diagnosis of vulval lichen sclerosis (54 years) and development of squamous cell carcinoma (74 years) has been reported (Carlson et al, 1998), and this is close to the age at which we see a sharp rise in incidence of vulval tumours in the United Kingdom (Figure 1).

We were also unable to distinguish between different types of squamous cell carcinomas. Keratinising squamous cell carcinomas are reported to be the most common histological subtype of vulval cancer in older women, and are less commonly HPV related (de Sanjosé et al, 2013). Of the 609 squamous cell carcinomas identified in our cohort, 131 (22\%) were specified as keratinising, whereas 447 (73\%) were 'squamous cell not otherwise specified'. We only had 8 registrations of tumours with warty (verrucous) morphology and no basaloid squamous cell tumours, the two morphologies most commonly associated with HrHPV infection. We were not able to tell whether tumours with typically HrHPVrelated morphologies are truly uncommon in our cohort or whether there is simply a lack of histopathological information captured during tumour registration. At best, tumour histology is a proxy marker of likely HPV association, but it would be helpful to have more robust evidence of histological subtype within the squamous cell group.

\section{CONCLUSION}

In a large cohort of over a million women with prospectively collected information on exposures, and just under 14 years of follow-up, we found that history of CIN 3 registration before recruitment, overweight and obesity, and younger age at menopause were associated with an increased risk of incident vulval cancer after the age of 50 years. We also observed a reduction in risk of melanocytic vulval cancers in women who had ever smoked; however, we interpret this finding with caution because of the potential role of chance. 


\section{ACKNOWLEDGEMENTS}

We thank the women and screening centre staff who participated in the Million Women Study. The Million Women Study is funded by Cancer Research UK (Grant No. C570/A16491) and the UK Medical Research Council (Grant No. MR/K02700X/1). K Coffey is supported by Cancer Research UK Grant Number C38302/A12981 through an Oxford Cancer Research Centre Prize DPhil Studentship. K Gaitskell is supported by Cancer Research UK (CRUK) Grant Number C38302/A17318 through a CRUK Oxford Centre Clinical Research Training Fellowship. K Canfell receives salary support from the National Health and Medical Research Council Australia (CDF \# 1082989).

\section{CONFLICT OF INTEREST}

The authors declare no conflict of interest.

\section{MILLION WOMEN STUDY COLLABORATORS}

Million Women Study Coordinating Centre staff: Hayley Abbiss, Simon Abbott, Rupert Alison, Miranda Armstrong, Krys Baker, Angela Balkwill, Emily Banks, Isobel Barnes, Valerie Beral, Judith Black, Roger Blanks, Kathryn Bradbury, Anna Brown, Benjamin Cairns, Dexter Canoy, Andrew Chadwick, Dave Ewart, Sarah Ewart, Lee Fletcher, Sarah Floud, Alicia Heath, Toral Gathani, Laura Gerrard, Adrian Goodill, Jane Green, Lynden Guiver, Michal Hozak, Isobel Lingard, Sau Wan Kan, Nicky Langston, Kath Moser, Kirstin Pirie, Gillian Reeves, Keith Shaw, Emma Sherman, Helena Strange, Sian Sweetland, Sarah Tipper, Lyndsey Trickett, Clare Wotton, Lucy Wright, Owen Yang, Heather Young.

Million Women Study Advisory Committee: Emily Banks, Valerie Beral, Lucy Carpenter, Carol Dezateux, Jane Green, Julietta Patnick, Richard Peto, Cathie Sudlow.

The NHS Breast Screening Centres that took part in the recruitment of participants were as follows: Avon, Aylesbury, Barnsley, Basingstoke, Bedfordshire and Hertfordshire, Cambridge and Huntingdon, Chelmsford and Colchester, Chester, Cornwall, Crewe, Cumbria, Doncaster, Dorset, East Berkshire, East Cheshire, East Devon, East of Scotland, East Suffolk, East Sussex, Gateshead, Gloucestershire, Great Yarmouth, Hereford and Worcester, Kent, Kings Lynn, Leicestershire, Liverpool, Manchester, Milton Keynes, Newcastle, North Birmingham, North East Scotland, North Lancashire, North Middlesex, North Nottingham, North of Scotland, North Tees, North Yorkshire, Nottingham, Oxford, Portsmouth, Rotherham, Sheffield, Shropshire, Somerset, South Birmingham, South East Scotland, South East Staffordshire, South Derbyshire, South Essex, South Lancashire, South West Scotland, Surrey, Warrington Halton St Helens and Knowsley, Warwickshire Solihull and Coventry, West Berkshire, West Devon, West London, West Suffolk, West Sussex, Wiltshire, Winchester, Wirral, Wycombe.

\section{REFERENCES}

Banks E, Beral V, Cameron R, Hogg A, Langley N, Barnes I, Bull D, Elliman J, Harris CL (2001) Agreement between general practice prescription data and self-reported use of hormone replacement therapy and treatment for various illnesses. J Epidemiol Biostat 6(4): 357-363.
Barlow EL, Kang YJ, Hacker NF, Canfell K (2015) Changing Trends in Vulvar Cancer Incidence and Mortality Rates in Australia Since 1982. Int $J$ Gynecol Cancer 25(9): 1683-1689.

Beral V. on behalf of The Million Women Study Collaborative Group (2003) Breast cancer and hormone- replacement therapy: the Million Women Study. Lancet 362(9392): 419-427.

Bobrow KL, Quigley MA, Green J, Reeves GK, Beral V (2012) Persistent effects of women's parity and breastfeeding patterns on their body mass index: results from the Million Women Study. Int J Obes 37(5): 712-717.

Brinton LA, Nasca PC, Mallin K, Baptiste MS, Wilbanks GD, Richart RM (1990) Case-control study of cancer of the vulva. Obstet Gynecol 75(5): 859-866.

Carlson JA, Ambros R, Malfetano J, Ross J, Grabowski R, Lamb P, Figge H, Mihm MC (1998) Vulvar lichen sclerosus and squamous cell carcinoma: a cohort, case control, and investigational study with historical perspective; implications for chronic inflammation and sclerosis in the development of neoplasia. Hum Pathol 29(9): 932-947.

Chaturvedi AK (2010) Beyond cervical cancer: burden of other HPV-related cancers among men and women. J Adolesc Health 46(4): S20-S26.

Coffey K, Beral V, Green J, Reeves G, Barnes I (2015) Lifestyle and reproductive risk factors associated with anal cancer in women aged over 50 years. Br J Cancer 112(9): 1568-1574.

Crawford R, Grignon A-L, Kitson S, Winder DM, Ball SLR, Vaughan K, Stanley MA, Sterling JC, Goon PKC (2011) High prevalence of HPV in non-cervical sites of women with abnormal cervical cytology. BMC Cancer 11(1): 473-478.

de Sanjosé S, Alemany L, Ordi J, Tous S, Alejo M, Bigby SM, Joura EA, Maldonado, Paula Laco J, Bravo IG, Vidal A, Guimerà N, Cross P, Wain GV, Petry KU, Mariani L, Bergeron C, Mandys V, Sica AR, Félix A, Usubutun A, Seoud M, Hernández-Suárez G, Nowakowski AM, Wilson G, Dalstein V, Hampl M, Kasamatsu ES, Lombardi LE, Tinoco L, Alvarado-Cabrero I, Perrotta M, Bhatla N, Agorastos T, Lynch CF, Goodman MT, Shin H-RR, Viarheichyk H, Jach R, Cruz MOLE, Velasco J, Molina C, Bornstein J, Ferrera A, Domingo EJ, Chou C-YY, Banjo A, Castellsagué X, Pawlita M, Lloveras B, Quint WGV, Muñoz N, Bosch FX (2013) Worldwide human papillomavirus genotype attribution in over 2000 cases of intraepithelial and invasive lesions of the vulva. Eur J Cancer 49(16): 3450-3461.

Franklin EW, Rutledge FD (1972) Epidemiology of epidermoid carcinoma of the vulva. Obstet Gynecol 39(2): 165-172.

Green TH, Ulfelder H, Meigs JV (1958) Epidermoid carcinoma of the vulva; an analysis of 238 cases. I. Etiology and diagnosis. Am J Obstet Gynecol 75(4): 834-847.

Japaze H, Garcia-Bunuel R, Woodruff JD (1977) Primary vulvar neoplasia: a review of in situ and invasive carcinoma, 1935-1972. Obstet Gynecol 49(4): 404-411.

Kalliala I, Anttila A, Pukkala E, Nieminen P (2005) Risk of cervical and other cancers after treatment of cervical intraepithelial neoplasia: retrospective cohort study. Br Med J 331: 1183-1185.

Kurman RJ, Carcangiu ML, Herrington CS, Young RH (eds) (2014) WHO Classification of Tumours of Female Reproductive Organs, 4th edn. IARC: Lyon, France.

Li Z, Wang Z, Yu Y, Zhang H, Chen L (2015) Smoking is inversely related to cutaneous malignant melanoma. Br J Dermatol 173(6): $1540-1543$.

Madsen BS, Jensen HL, van den Brule AJC, Wohlfahrt J, Frisch M (2008) Risk factors for invasive squamous cell carcinoma of the vulva and vaginapopulation-based case-control study in Denmark. Int J Cancer 122(12): 2827-2834.

Newcomb PA, Weiss NS, Daling JR (1984) Incidence of vulvar carcinoma in relation to menstrual, reproductive, and medical factors. J Natl Cancer Inst 73(2): 391-396.

Office for National Statistics (2014) Cancer Statistics Registrations, England, Series MB1. Available at: http://www.ons.gov.uk/ons/publications/rereference-tables.html?edition=tcm:77-262496.

Parazzini F, La Vecchia C, Garsia S, Negri E, Sideri M, Rognoni MT, Origoni M (1993) Determinants of invasive vulvar cancer risk: an Italian case-control study. Gynecol Oncol 48: 50-55.

StataCorp (2015) Stata Statistical Software: Release 14. StataCorp LP: College Station, TX, USA.

Townsend P (1987) Deprivation. J Soc Policy 16: 125-146. 
van de Nieuwenhof HP, van Kempen LCLT, de Hullu JA, Bekkers RLMM, Bulten J, Melchers WJGG, Massuger LFAG (2009) The etiologic role of HPV in vulvar squamous cell carcinoma fine tuned. Cancer Epidemiol Biomark Prev 18(7): 2061-2067.

Webb PM (2013) Obesity and gynecologic cancer etiology and survival. Am Soc Clin Oncol Educ Book; doi:10.1200/EdBook_AM.2013.33.e222.

World Health Organization (2000) International Classification of Diseases for Oncology, 3rd edn. World Health Organization. Available at: http:// www.who.int/classifications/icd/adaptations/oncology/en/.
World Health Organization (2011) International Statistical Classification of Diseases and Related Health Problems-10th Revision.

This work is published under the standard license to publish agreement. After 12 months the work will become freely available and the license terms will switch to a Creative Commons AttributionNonCommercial-Share Alike 4.0 Unported License.

Supplementary Information accompanies this paper on British Journal of Cancer website (http://www.nature.com/bjc) 